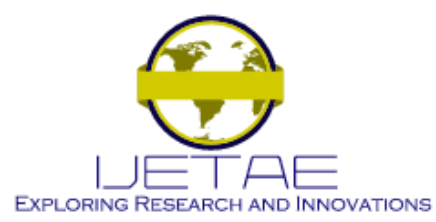

International Journal of Emerging Technology and Advanced Engineering

Website: www.ijetae.com (ISSN 2250-2459, ISO 9001:2008 Certified Journal, Volume 10, Issue 11, November 2020)

\title{
Application of Simulation Software in Optimization of Powertrain of Pure Electric Vehicle
}

\author{
Baoqi Ma ${ }^{1}$, Zhenping $\mathrm{Wan}^{2}$, Zhibiao $\mathrm{Hu}^{3}$, Zhantong $\mathrm{Li}^{4}$, Chongyang $\mathrm{Han}^{5}$, Zhiheng Zeng ${ }^{6}$, Zefeng Zheng ${ }^{7}$, \\ Ting Tang ${ }^{8}$, Weibin $\mathrm{Wu}^{9}$ \\ 1,3,4,5,6,7,8 College of Engineering, South China Agricultural University, Guangzhou 510642, China \\ ${ }^{2}$ China School of Mechanical and Automotive Engineering, South China University of Technology, Guangzhou 510640,China
}

\begin{abstract}
Pure electric vehicles are a research hotspot in today's new energy vehicle industry. Its core is the electromechanical coupled drive system (drive motor and gearbox), and its performance affects the overall performance of pure electric vehicles. The application of industrial software for electromagnetic design, electrothermal design, electromagnetic vibration and noise optimization of drive motors, heat transfer analysis, fatigue analysis, and noise optimization analysis of gearboxes has become important technologies for designing and manufacturing the core components of electromechanical coupling drive systems.This article analyzes the current status and existing problems of the development of simulation software for the core components (drive motor and gearbox) of the electromechanical coupling drive system of electric vehicles, and proposes solutions to key technical problems, and proposes the development direction of unified simulation of drive motor and gearbox on the electromechanical coupling platform.
\end{abstract}

Keywords - drive motor; gearbox; simulation analysis; industrial software

\section{RESEARCH BACKGROUND AND IMPORTANCE}

With the rapid economic and social development, countries all over the world are facing the problems of energy depletion and environmental destruction. The continuous increase in car ownership will consume more fossil fuel resources. At the same time, the environmental pollution caused by exhaust gas has become increasingly severe, which has become a concern of the world. Therefore, there is an urgent need to develop new energy vehicles that can maintain the sustainable development of mankind and the peaceful coexistence of the environment.Compared with traditional fuel vehicles, new energy vehicles have different forms of energy supply. Great changes have taken place in the layout of the vehicle and the drive system assembly. The drive system assembly is very important to the performance of the vehicle.,because it not only undertakes the bearing function and driving function, but also directly determines the safety and comfort of the whole vehicle.
It is very necessary to develop low noise, high efficiency, high power density and long life. Centralized drive mode,as shown in Figure 1,is now the mainstream driving mode of electric vehicles.In the centralized drive mode, the high- power density drive motor replaces the traditional fuel engine. At the same time, the mechanical transmission system and braking system of the fuel vehicle are retained.In terms of power transmission, it retains the original transmission gearbox, differential and transmission shaft; in the matching of the drive motor, the permanent magnet synchronous motor has the advantages of power density, efficiency, and high power factor. It eliminates the DC motor and PM Brushless DC motors, switched reluctance motors, and $\mathrm{AC}$ induction motors becoming the mainstream choice for electric vehicle drive motors ${ }^{[1]}$.Simulation technology is based on control theory, similarity theory, information processing technology and calculation technology, and uses computers and other special equipment as tools , and uses system mathematical models to test the real or imaginary test objects ${ }^{[2]}$. The electromagnetic design of motor,the electrothermal design of motor,the optimization of electromagnetic vibration and noise of motor,the analysis of heat transfer of the gearbox,the analysis of the fatigue of the gearbox and the optimization analysis of noise of the gearbox plays a vital role in the process of designing the drive motor and gearbox. However, the motor electromagnetic design software companies are mainly companies such as Ansys and Jmag, and gearbox and mechanical design simulation software companies include SMT Technology, Romax, and Gleason. Most of the software developed by these companies is limited to a specific field. All lacks the ability to analyze the overall design and analysis of the electromechanical coupling system. This article reviews the electromagnetic design of motor, the electrothermal design of motor,the optimization of electromagnetic vibration and noise of motor,the analysis of heat transfer of the gearbox,the analysis of the fatigue of the gearbox and the optimization analysis of noise of the gearbox.And the future development direction of simulation industrial software is pointed out. 


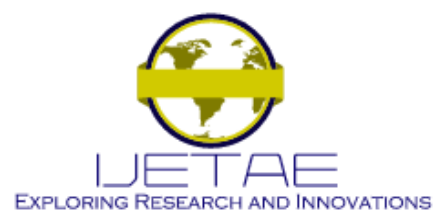

International Journal of Emerging Technology and Advanced Engineering Website: www.ijetae.com (ISSN 2250-2459, ISO 9001:2008 Certified Journal, Volume 10, Issue 11, November 2020)

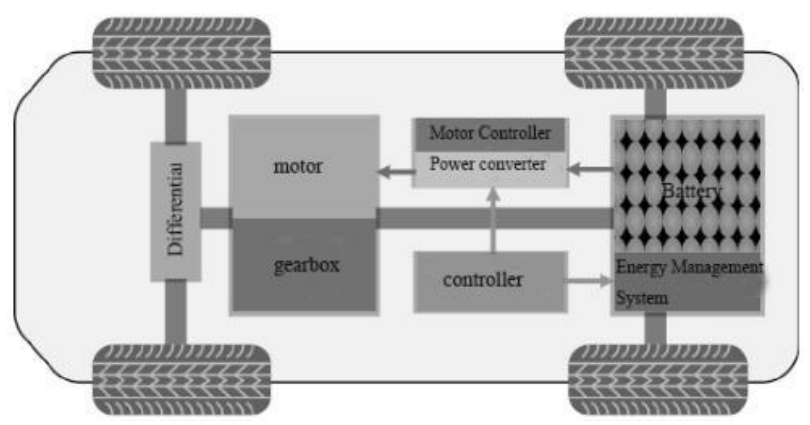

Fig 1 Centralized drive mode ${ }^{[1]}$

\section{EleCtromagnetic Design And Simulation OF THE DRIVE MOTOR}

Electromagnetic design of drive motor is to use simulation software to analyze the designed motor after completing the basic size design of the drive motor, and check whether the motor design performance meets the requirements. In the field of motor electromagnetic field analysis, a variety of effective finite element simulation software has been born, the commonly used are: Ansoft Maxwell, ANSYS, magnet, motor solve, flux, and so on. Ansoft Maxwell and magnet, as electromagnetic simulation software, are particularly suitable for the finite element analysis of the motor electromagnetic field, while motors over is a special finite element analysis software for the motor electromagnetic field. The modeling and simulation of permanent magnet synchronous motor is mainly finite element modeling and analysis represented by ANSYS Maxwell or Ansoft Maxwell simulation. In the finite element analysis, the electromagnetic model is subdivided by meshing, and the infinite number of real systems is approximated by a finite number of unknowns using mathematical approximation ${ }^{[3]}$.At present, the finite element analysis of the electromagnetic field plays an irreplaceable role in the design and optimization of the motor body.

\section{A. Requirement analysis of electromagnetic simulation of the drive motor}

The operation of the motor in the complex electromagnetic multi-physical field environment can not be simply attributed to the performance of the driving motor itself, so it is necessary to analyze the driving motor under multiple working conditions. First of all, to test whether the magnetic density of stator and rotor teeth in the main magnetic circuit of the designed drive motor will have a great impact on the motor performance, the no-load performance of the drive motor must be analyzed.
The no- load magnetic field distribution diagram, no-load air gap flux density waveform, no-load back EMF waveform, and no-load back EMF are solved by finite element analysis software, and then the influence of stator and rotor tooth magnetic density of main magnetic circuit on motor performance under no-load condition is judged.

Secondly, to further optimize the rotor magnetic bridge and reduce the phenomenon of flux leakage and magnetic saturation of the motor at rated load, and then analyze the flux weakening angle under different current of the motor, and better consider the permanent magnet torque and synchronous torque, it is necessary to analyze the magnetic field distribution of the motor at rated load. The electromagnetic torque curve under different current and flux weakening angle and the torque fluctuation curve under different current and flux weakening angle are solved by software. Based on the curve, the rotor magnetic bridge is optimized.

Besides, flux weakening control is needed when the motor is running at high speed. However, the experiment shows that the loss of excitation characteristics of permanent magnet synchronous motor for the electric vehicle under high temperature and high current is necessary because the electric vehicle needs to have the ability to run at high speed and high load for a long time. The permanent magnet loss of excitation will cause the working point to move down, the magnetism will be weakened, and the average torque of the motor will be reduced. To avoid the permanent magnet loss of excitation fault caused by the current reaching several times of the maximum operating current under flux weakening control, it is necessary to analyze the loss of excitation characteristics. Through the software to solve the schematic diagram of permanent magnet loss of the excitation area and the output torque waveform of the permanent magnet under the different loss of excitation, the flux weakening angle can be adjusted appropriately based on this.

Whether the distribution of magnetic flux density is reasonable, especially the flux density at the magnetic separation bridge is analyzed, which is related to whether the magnetic density can reach the high saturation and limit the leakage phenomenon. The air gap is the place of energy storage and electromechanical energy conversion, so the noload air gap flux density distribution affects the parameters and performance of the motor. Using the modeling function provided by the finite element software, the two-dimensional simulation model of high- power density permanent magnet synchronous motor is established. The two-dimensional static magnetic field solver is used to solve the model directly. 


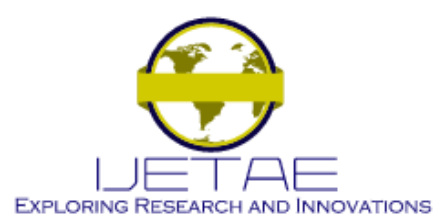

\section{International Journal of Emerging Technology and Advanced Engineering Website: www.ijetae.com (ISSN 2250-2459, ISO 9001:2008 Certified Journal, Volume 10, Issue 11, November 2020)}

Through the software, the flux density distribution diagram of PMSM, the flux line distribution diagram of PMSM, and the magnetic field intensity distribution map of the PMSM air gap line are solved. The rationality of the magnetic flux density of the motor is judged.

Finally, by analyzing the relationship between the phase winding flux and time, it can be explained whether the stator three-phase winding is set correctly or not. Therefore, it is necessary to analyze the transient field of the motor. To reduce the amount of calculation, shorten the solution time and improve the efficiency of the solution, considering the symmetry of the motor, the motor area occupied by a permanent magnet pole can be taken as the solution object in the transient analysis of the motor based on finite element software. The flux linkage of the three- phase winding and the back EMF of the three-phase winding is obtained by using the transient field solver. To verify the correctness of the stator three- phase winding set ${ }^{[3-4]}$.

\section{B. Difficulties and challenges in the electromagnetic simulation of the drive motor}

In the finite element analysis, the electromagnetic model is subdivided by meshing, and the infinite number of real systems is approximated by a finite number of unknowns using mathematical approximation. The finite element analysis has high accuracy and a large amount of calculation, and with the refinement of mesh generation, the calculation accuracy and calculation amount will increase. With the continuous development of drive motor electromagnetic design technology and related field technology, the scale and complexity of electromagnetic simulation problems continue to develop in-depth, especially the dynamic electromagnetic simulation has become a hot spot in the simulation field: on the one hand, the driving motor entity model is becoming more and more complex, and the simulation calculation is more and more large, which puts forward higher requirements for hardware equipment; on the other hand, the dynamic electromagnetic simulation has become a hot topic in the simulation field In the process of electromagnetic design simulation, the amount of information interaction between the distributed nodes is increasing, which makes the communication consumption of the whole simulation more and more large; moreover, the simulation speed of each simulation node is difficult to keep consistent, which greatly hinders the efficiency of the overall simulation time moving forward, and then affects the operation efficiency of the global simulation.
With the increasing complexity of the scale of the model, the demand for the computing power of the computer will also increase. Therefore, how to reasonably and effectively apply high-performance computing environment to the electromagnetic simulation of drive motor has become a problem with practical application requirements and theoretical research value.

\section{Application example of electromagnetic simulation of the drive motor}

This paper introduces the analysis of soft permanent magnet synchronous motor based on Ansoft Maxwell finite element analysis. Ansoft Maxwell is a powerful and accurate software for electromagnetic simulation calculation of the electromechanical system. Based on Maxwell's equations theory, various types of 2D / 3D electromagnetic fields, such as static magnetic field, electrostatic field, constant electric field, and transient magnetic field, are solved by the finite element method. Due to the continuous innovation of technology, with the update of the Ansoft Maxwell version, more and more solving functions are increasing. When solving electromagnetic problems, the analysis speed is constantly improved, and the analysis accuracy is also more and more accurate...

Based on Ansoft The simulation of permanent magnet synchronous motor based on Maxwell finite element analysis software includes several main parts: 1) according to the designed rotor size parameters, stator size parameters and stator slot size parameters, a two- dimensional simulation model is built in the finite element simulation software; 2) according to the requirements of motor design, the materials of each part of the two-dimensional simulation model are reasonably distributed, and the stator and rotor materials are set 3 ) the motor excitation source is set in the two-dimensional simulation model model, and the voltage source or current source excitation is correctly set for the three- phase winding of the motor; 4) the boundary conditions of the simulation model are set; for the global simulation model, the external boundary of the motor is usually set as $\mathrm{a}=0 \mathrm{web} / \mathrm{m}$, that is, there is no magnetic leakage at the motor boundary; 5) the two-dimensional simulation model is reasonably divided. The mesh fraction of the model is designed reasonably according to the required solution accuracy; 6) after the above steps are completed, start to solve and view the solution results, as shown in Figure 2. 


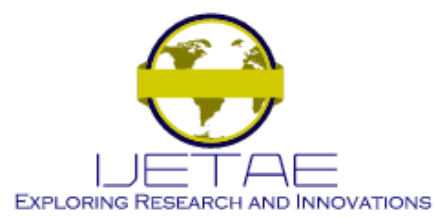

International Journal of Emerging Technology and Advanced Engineering Website: www.ijetae.com (ISSN 2250-2459, ISO 9001:2008 Certified Journal, Volume 10, Issue 11, November 2020)

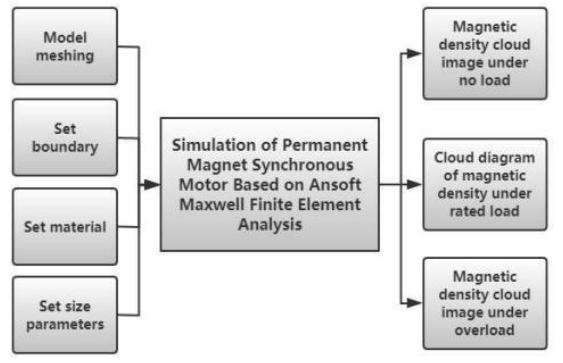

Fig 2 Simulation diagram of soft permanent magnet synchronous motor based on Ansoft Maxwell finite element analysis

According to the given requirements, the development researcher designs the pole slot coordination of the motor. According to the speed and torque of the motor, the basic size of the motor is estimated first. Then, based on the speed magnetic circuit design software, the motor winding turns, permanent magnet size, punching size, and rotor structure size are designed.

According to the design results, the rated performance, overload performance, no-load performance, flux weakening performance, and other important working conditions are analyzed by Ansoft Maxwell. The rated magnetic density cloud diagram, overload magnetic density cloud diagram, and no-load magnetic density cloud diagram of the motor are solved by software ${ }^{[5]}$.Based on the results of the solution, the single or multiple parameters of the motor are optimized until the motor meets the use requirements, to guide the electromagnetic design of the drive motor according to the simulation results. The cloud map of magnetic field density distribution is shown in Figure3.

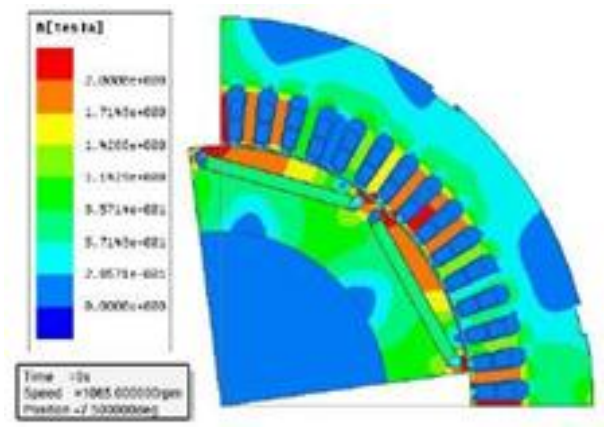

Fig3 Cloud map of magnetic field density distribution ${ }^{[5]}$

\section{Electric Heating ANAlysis AND Simulation OF A DRIVE MOTOR}

When the motor is running, there is an interaction between the electromagnetic field and the temperature field.
Therefore, the operation of the motor is a multi- physical field problem, that is, electromagnetic thermal coupling problem. On the one hand, the power loss generated by the current in the winding is converted into a heat source during the operation of the motor. On the other hand, the magnetic properties of the motor will change due to the temperature rise, which will affect the stator winding. Therefore, the relationship between the electromagnetic field and the temperature field is of mutual influence. The temperature field calculation and analysis of the motor is a multi-field coupling problem. When solving the multi-field coupling problem, the current mainstream solution method is a sequential coupling. Firstly, the electromagnetic field of the motor is analyzed, and then the temperature field of the motor is analyzed. The analysis of the model by sequential coupling is simple and easy to understand, the condition setting is convenient, and the computer requirements are not high, which can meet the solution of motor temperature field $^{[6]}$.

\section{A. Electric heating analysis and simulation requirements of the drive motor}

To meet the requirements of vehicle electric drive power density, the electromagnetic load of driving motor is often designed to be very high, and the motor operating environment temperature is high, the ventilation and heat dissipation effect is poor, and the cooling medium temperature is high. Therefore, accurate motor thermal analysis and calculation is the key to the design of high power density electric drive permanent magnet motor ${ }^{[7]}$. However, the traditional temperature rises calculation method based on equivalent thermal resistance is simple and efficient, but it is difficult to meet the requirements of accurate calculation of temperature rise of permanent magnet drive motor with a highly coupled electromagnetic field, fluid field, and temperature field. Also, the back EMF harmonic estimation of permanent magnet temperature rise can avoid the loss distribution which is difficult to calculate and directly estimate the permanent magnet temperature, but it can not calculate the overall temperature distribution of the motor. Therefore, using finite element analysis software to simulate the temperature rise of the motor is an essential step in the process of motor design ${ }^{[4]}$.

\section{B. Difficulties in electric heating analysis and Simulation of the drive motor}

Firstly, the temperature rises simulation needs to calculate the loss and its distribution, and need to consider the heat dissipation conditions of the motor. The loss of motor mainly includes several parts: copper loss, iron loss, mechanical loss, and stray loss. 


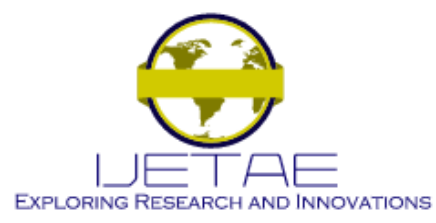

International Journal of Emerging Technology and Advanced Engineering

Website: www.ijetae.com (ISSN 2250-2459, ISO 9001:2008 Certified Journal, Volume 10, Issue 11, November 2020)

In the motor loss, only copper loss and iron loss can be calculated by relevant software, and the rest loss is generally given by a certain proportion of output power, which will affect the accuracy of the temperature rise simulation model.Secondly, the heat dissipation condition of the motor is also one of the factors that determine the temperature rise of the motor. The software integrates many kinds of heat dissipation forms, which is convenient for calculation, but also leads to the selection of convective heat transfer coefficient of the model, which will greatly affect the reliability of temperature rise simulation. How to choose the convective heat transfer coefficient reasonably according to different materials and different heat dissipation conditions is a difficult point in temperature rise simulation.

\section{An example of electric heating analysis and Simulation of the drive motor}

Taking the coupled simulation of motor temperature rise based on Maxwell and ANSYS Workbench as an example.

There are many kinds of motor temperature field simulation software, such as ANSYS Workbench, motor CAD, and so on. ANSYS Workbench software integrates the calculation idea of finite element software. Similar to Maxwell, it needs modeling, subdivision, material assignment, boundary conditions, and calculation. The coupling simulation of Maxwell and ANSYS Workbench is to directly import Maxwell's calculation model and results into the ANSYS Workbench, which saves a lot of modeling work of ANSYS Workbench. Among them, the data exported by Maxwell includes the loss of motor. Because the simulation of the two-dimensional steady- state field of the motor, Maxwell needs to calculate the two- dimensional static magnetic field. Finally, the whole process of ANSYS Workbench temperature field simulation is divided into modeling, material assignment, subdivision, boundary conditions, solution, etc. The temperature distribution program of the motor is obtained. The temperature bearing capacity of the motor winding and the maximum temperature of the winding are compared to determine whether the cooling structure of the motor needs to be optimized for cooling, to guide the design of the motor cooling system ${ }^{[4,8]}$.Coupling simulation flow of motor temperature rise by Maxwell and ANSYS Workbench is shown in Figure4 and the Simulation results in ANSYS Workbench is shown in Figure 5.

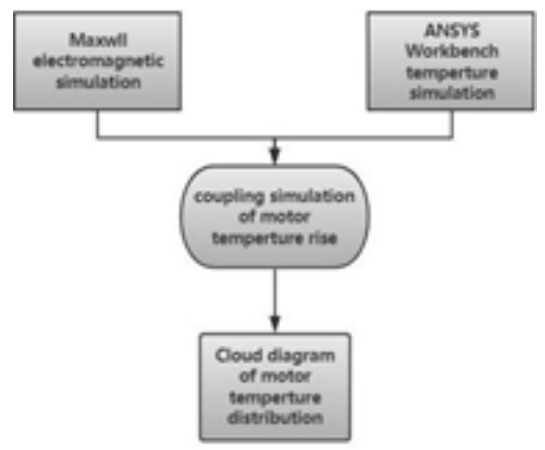

Fig 4 Coupling simulation flow of motor temperature rise by Maxwell and ANSYS Workbench.

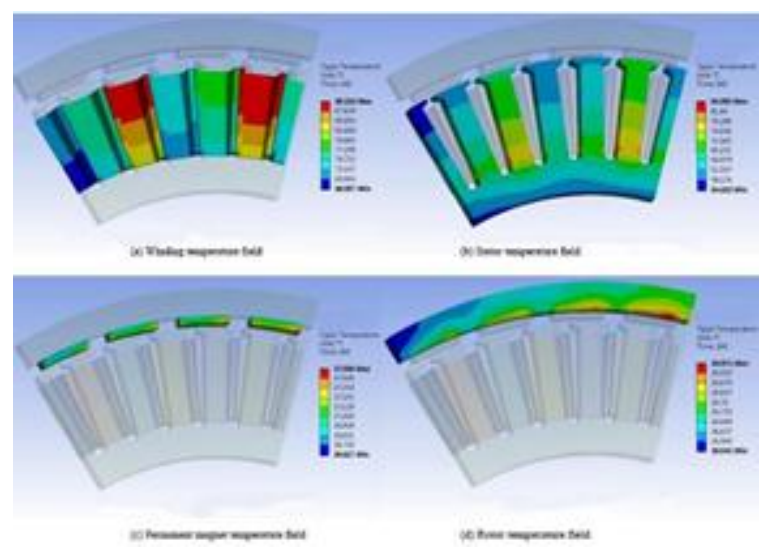

Fig 5 Simulation results in ANSYS Workbench ${ }^{[4]}$

\section{Optimization Simulation OF ElECTROMAGNETIC VIBRATION AND NoISE OF DRIVE MOTOR}

For a permanent magnet synchronous motor, the electromagnetic force acting on the rotor can be divided into radial electromagnetic force and tangential electromagnetic force theoretically. The tangential force causes the armature to torque and operate. Besides, the fluctuation of the radial electromagnetic force will cause the vibration of the motor, which will cause the vibration and noise of the motor $^{[9]}$.According to Maxwell's stress tensor theory in the air gap of permanent magnet synchronous motor (PMSM), the air gap flux density can be optimized by the algorithm to reduce the electromagnetic radial force and optimize the vibration noise. 


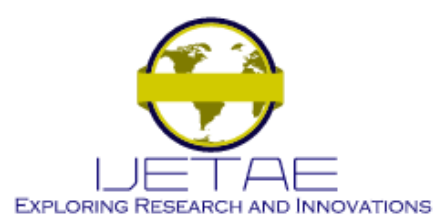

\section{International Journal of Emerging Technology and Advanced Engineering Website: www.ijetae.com (ISSN 2250-2459, ISO 9001:2008 Certified Journal, Volume 10, Issue 11, November 2020)}

In addition to the radial electromagnetic force of the stator structure, the electromagnetic vibration noise of the permanent magnet synchronous motor is also related to the radial modes of the stator structure ${ }^{[10]}$. When the frequency and frequency of electromagnetic force wave are equal to or close to the natural frequency of stator, the electromagnetic force will strengthen the noise radiation of stator casing. The complete and accurate modal description can be obtained by vibration and modal analysis of stator structure, which can provide data support and theoretical reference for reducing the noise of motor and designing and optimizing the stator structure.

At present, the mainstream vibration and noise optimization method is the joint simulation of the transient dynamic analysis module in ANSYS Workbench and electromagnetic design module of Maxwell.

\section{A. Simulation requirements of electromagnetic vibration and noise optimization of the drive motor}

Firstly, the inherent mode analysis of permanent magnet motor stator is carried out. It includes a stator core, winding, casing, and end cover, and other rigid structures, all of which will affect the stator mode. The frequency of electromagnetic resonance caused by different vibration modes is different. It is necessary to study the vibration mode of permanent magnet synchronous motor stator with the help of the modal analysis method of finite element simulation. According to the basic principle of modal analysis, modal analysis of the motor core is carried out, and the vibration modes of each part of the motor vibration are obtained. On this basis, the motor speed and electromagnetic force are aimed to wave frequency to avoid electromagnetic resonance are studied ${ }^{[11]}$.

\section{B. Difficulties in optimization simulation of electromagn- etic vibration and noise of drive motor}

In the modal analysis of stator, the key problem is to define a suitable material. In practice, the stator core is made of a silicon steel sheet, which is a heterogeneous elastic body and can not be replaced by silicon steel. The current method is to measure the density, Young's modulus, and Poisson's ratio of stator core material to define the core material.

Also, the complexity of the motor model and the amount of simulation calculation put forward higher requirements for the hardware equipment. How to reasonably simplify the solid model and reduce the simulation calculation amount will speed up the motor modal analysis and reduce the development time.

\section{An optimization simulation example of electromagnetic vibration and noise of drive motor}

Based on ANSYS Workbench and Maxwell, an example of a joint simulation of electromagnetic vibration of the motor is given. Firstly, the modal analysis of the stator core of the built-in permanent magnet motor is carried out by using ANSYS Workbench software. The three-dimensional modeling of the stator core is carried out, and the material parameters are defined. Then the modal analysis is carried out to calculate the natural frequencies of the stator core. Through the equivalence of stator winding, the finite element analysis model of the stator with winding is established, and the radial modal frequency of each order is analyzed. SolidWorks software is used to build the model of the casing and end cover, and the modal analysis is carried out after adding constraints. According to the vibration modal analysis of each part of the stator, the whole modal frequency of the stator is deduced. Then, the electromagnetic vibration of the motor under no-load and load is analyzed. In this paper, the electromagnetic vibration of the motor under no-load, load, no-load speed, and different harmonic current frequency is obtained through the joint simulation of electromagnetic vibration, to study the electromagnetic vibration when the electromagnetic force wave reaches the resonance mode, and guide the optimization of electromagnetic vibration scheme based on this ${ }^{[12]}$.

\section{Gearbox Fatigue Analysis Simulation}

The fatigue life of the gearbox directly affects the reliability and safety performance of the automobile. As a key component of the gearbox, the life of the gear depends largely on the contact fatigue life of the gear. In the process of car driving, due to changes in driving speed, changes in road characteristics, and complex changes in driving conditions, the output torque of the motor and the driving torque of the driving wheels have great randomness ${ }^{[13]}$.The gearbox serves as a transmission motor torque to the transmission structure of the driving wheel is bound to bear great randomness in the torque. Under such random load cyclic disturbance, the gearbox gear bears random load, which will easily cause contact fatigue damage to the gear and cause the gearbox to fail to work normally. , Affecting the reliability and safety of the $\operatorname{car}^{[14]}$.

\section{A. Gearbox fatigue analysis simulation requirements}

It is necessary to select an appropriate cumulative damage theory. The amplitude of the cyclic load on most parts of the gearbox varies, that is to say, these are all working under variable amplitude loads. 


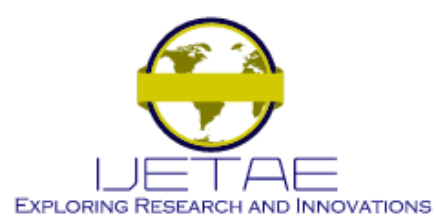

\section{International Journal of Emerging Technology and Advanced Engineering Website: www.ijetae.com (ISSN 2250-2459, ISO 9001:2008 Certified Journal, Volume 10, Issue 11, November 2020)}

Fatigue failure under variable amplitude loads is the result of the gradual accumulation of damage caused by loads of different frequencies and amplitudes ${ }^{[15]}$. In the fatigue analysis of gearboxes, generally three types of cumulative damage theories are commonly used, and their respective application ranges are as follows: Linear fatigue cumulative damage theory is suitable for calculation of high-cycle fatigue life, and can better predict the average fatigue life. The linear cumulative damage theory refers to the linear relationship between damage accumulation and the number of cycles, including Miner's law and relative Miner's law; the modified linear fatigue cumulative damage theory is suitable for low-cycle fatigue life calculations; while the nonlinear fatigue cumulative damage theory is for secondary loading The fatigue life estimation of the situation is more effective. Non- linear cumulative damage theory includes damage curve method and Corten-Dolan theory ${ }^{[16]}$

The influence of optimized meshing on fatigue analysis. The accuracy of the gearbox finite element analysis model is directly related to the finite element mesh used ${ }^{[17]}$.The finite element mesh is used to divide the model into many smaller domains, which we call elements, and then solve a set of equations on these elements. These equations approximate the expressions by a set of polynomial functions defined on each element.

The required governing equations. With the continuous refinement of the grid, these units become smaller and smaller, so that the solution result is getting closer and closer to the real solution ${ }^{[18]}$.

Reduce the influence of relative stress gradient on the simulation process. The influence of relative stress gradient is very important for the simulation of fatigue analysis ${ }^{[19]}$. Whether it is damage analysis or fatigue safety factor and static safety factor analysis, the relative stress gradient must be considered to consider the influence of stress concentration. Similar to FEMFAT or ANSYS and other software for fatigue analysis, almost all modules consider this influencing factor, not only to modify the SN curve, but also to modify the Hager diagram. It can be said that the relative stress gradient is the most influential in fatigue analysis. An important parameter.

\section{B. Difficulties and challenges of gearbox fatigue analysis simulation}

In terms of fatigue analysis, the gearbox fatigue life simulation analysis is generally based on the gearbox gear transmission system or gearbox assembly model, and then the finite element simulation method generally includes two types: First, the gearbox is simplified to a single pair Gear, and then use the uniaxial fatigue theory to simulate and analyze it under the condition of considering only certain factors that affect the life of the gear, but the simulation results obtained by this method are somewhat different from the experimental conclusions, because it does not consider the gear dynamics The effect of load on the fatigue life of the gearbox; another method is to use the principle of multiaxis fatigue analysis to establish a simulation model of the entire gearbox in consideration of the overall factors affecting the gearbox, but in actual operation, the model will be found to be too complicated, And the calculation efficiency is very $l_{0}{ }^{[20]}$.In addition, the current fatigue theory cannot fully analyze the mechanism of certain effects in the formation and propagation of micro-cracks in gearbox gears $^{[21]}$.Therefore, various methods developed on this basis are in some cases .It may lead to a large error in the results. Various fatigue analysis finite element methods are very sensitive to stress types and action modes ${ }^{[22]}$. These factors are often not accurately obtained in actual engineering, resulting in considerable dispersion of results; when performing fatigue analysis, finite element analysis software It is difficult to prejudge the dangerous area of the gearbox fatigue damage, and it is obviously not realistic to carry out detailed modeling and analysis of all the nodes where initial cracks may occur, plus uncertain factors such as the complexity of the load time history, The dispersion of model test results, residual stress and corrosion effects, etc., may cause the results to have magnitude deviations from the actual situation ${ }^{[23]}$.

\section{Examples of gearbox fatigue simulation analysis}

The fatigue analysis of gearbox gears based on ABAQUS software can be divided into the following steps ${ }^{[24]}$ : 


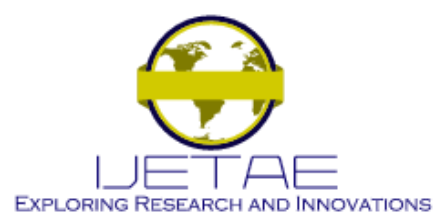

\section{International Journal of Emerging Technology and Advanced Engineering Website: www.ijetae.com (ISSN 2250-2459, ISO 9001:2008 Certified Journal, Volume 10, Issue 11, November 2020)}

(1) To finite element analysis. To import the established 3D model into the ABAQUS software and define the section properties and material properties, and then set the elastic modulus, Poisson's ratio and density values, to define the gear contact pair, and divide the mesh, and set different load steps to distinguish between contact and load The load is applied last.

(2) Stress and life analysis. To analyze the influence of gear length, ring gear thickness, wall thickness and tooth root transition fillet on stress and life. The results of different stress and life data at the same level are averaged, and the average of each level is polynomial fitting to obtain a fitting curve.

(3) Stress analysis and calculation. To import the threedimensional model into ANSYS and define the contact surface and the target surface after meshing, perform full- degree- of-freedom constraints, set the analysis type, time, step length, etc., and perform the solution calculation to obtain the bending stress cloud diagram.

(4) Reliability analysis. The Monte Carlo method is used to determine the gear stress and strength distribution type, and the reliability analysis model is obtained, and then the reliability analysis of the gear tooth bending stress and strength can be carried out. The Figure6 shows the flow chart of fatigue analysis of gearbox gear based on ABAQUS software.

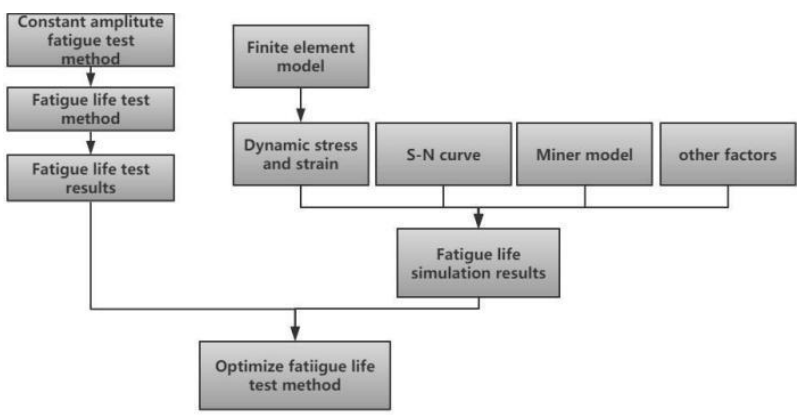

Fig 6 Flow chart of fatigue analysis of gearbox gear based on ABAQUS software

Researchers used ABAQUS for gearbox gear fatigue design. Based on the orthogonal design method, the structural parameters of the flexspline are combined within a certain range, and ABAQUS stress analysis and FESAFE fatigue life analysis are performed on the flexspline. The fitting curve of ring thickness, flexspline wall thickness, tooth width and excessive fillet at the root of the tooth to the maximum equivalent stress and the number of fatigue cycles are analyzed.
Various parameters are analyzed to study the influence of each parameter on stress and life. Then complete the gearbox gear reliability calculation: Based on the stress intensity interference theory, Monte Carlo method is introduced to analyze the gear reliability, calculate the flexspline reliability, and compare and analyze the calculation results with the numerical integration method. Reliability analysis and design provide new ideas.

\section{Gearbox Heat Transfer Analysis Simulation}

There are three methods for analyzing the heat transfer of gearboxes: experimental method, finite element method and thermal network method ${ }^{[25]}$. The purpose of the experimental method is to measure the temperature of the gear box, and it can be tested intuitively and reliably through thermocouple or infrared equipment, but limited by the test conditions and equipment, it has high cost, and the experimental data is easily affected by external interference and cannot be fully obtained $^{[26]}$.The thermal state parameters of the gearbox and other shortcomings; the applicable condition of the finite element method is to study the overall modeling of the system and simulate simple and regular-shaped objects. For overly complex systems, the use of the finite element method tends to simplify the modeling, which will lead to the inaccuracy of later calculations; the thermal network method is to simplify the analysis system into a number of isothermal nodes, and connect the nodes to form a thermal network through thermal resistance. It has been widely used in automobiles, rail transit, aerospace and other fields ${ }^{[27]}$.

\section{A. Simulation requirements for gearbox heat transfer analysis}

The equilibrium temperature of gearbox gears during operation is related to many factors ${ }^{[28]}$ : such as the arrangement of various components in the gearbox, gear types, structural parameters, materials, and operating load during operation. The situation of different gearboxes varies greatly, and it is difficult to analyze and calculate through a single empirical formula. At present, the heat transfer analysis inside the gearbox is mainly conducted through experiments and simulation methods, but the results and extracted data that can be viewed in the experiment are very limited and have certain limitations. Through the simulation analysis method combining the flow field and the temperature field can effectively conduct in-depth research on the heat transfer analysis of the gearbox ${ }^{[29]}$. 


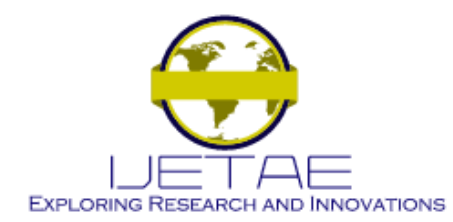

\section{International Journal of Emerging Technology and Advanced Engineering Website: www.ijetae.com (ISSN 2250-2459, ISO 9001:2008 Certified Journal, Volume 10, Issue 11, November 2020)}

(1) The heat source calculation of gearbox gears is completed by simulation software. Analytical method is used to calculate the frictional heat flow generated by gearbox gears during meshing. The heat flow density distribution on the meshing tooth surface of the gears during meshing is obtained through thermal simulation software, and the heat flow density and loss power obtained from theoretical calculations are compared. The flow field simulation calculates the wind resistance loss of the gearbox gear ${ }^{[30]}$.

(2) To complete the flow field and temperature field analysis. To calculate the distribution of the convective heat transfer coefficient of the gearbox gear, and calculate the corresponding power loss of the gear according to the flow field analysis result. On the basis of the heat flow boundary and convection heat transfer coefficient, the temperature field analysis is carried out to calculate the temperature distribution of the gear. At the same time, on the basis of the convection heat transfer obtained from the flow field,the Fluent software is re-developed, and the temperature field is calculated by writing a program to apply a heat source that changes with the tooth surface position to the meshing tooth surface $^{[31]}$.

(3) To analyze whether the gear speed will have a greater impact on the temperature field. The final balance process of the gear train in the gearbox is a process in which multiple physical quantities affect each other. The balance temperature will be affected by multiple factors such as the load of the gear and the layout of the gearbox ${ }^{[32]}$.Through thermal simulation software, the analysis method of flow field combined with temperature field is used to study the influence of gear speed, gear heat generation, gear surface convective heat transfer coefficient and temperature distribution, and analyze the influence of various variables on the gear temperature field, and pass post-processing CFDPost extracts the data of the wind resistance loss power and meshing loss power of the gear ${ }^{[33]}$.

(4) To complete the simulation analysis of the gearbox. First, it is necessary to eliminate the influence of modeling on the simulation analysis. Therefore, preprocessing should be carried out. The case, shaft system and gears of the planetary gear system should be simplified without affecting the fluid flow space and calculation accuracy to increase the calculation speed. Only then can the simplified model be imported into Fluent for boundary condition setting.
Then you need to consider whether the gear meshing loss power is within a reasonable range. The meshing loss can be applied to the corresponding position on the gear surface through UDF, and the thermal balance analysis is performed on the basis of the gear model obtained by the flow field analysis, and the temperature field of the gearbox is calculated ,to verify the accuracy of the simulation results.

\section{B. Difficulties and challenges of gearbox heat transfer analysis simulation}

For the gearbox heat transfer analysis, during the transmission process, the gearbox bearings, gears and other moving parts will produce a certain power loss due to friction, and this part of the lost power is based on heat ${ }^{[34]}$.The form is released. Due to different working conditions, the types of friction loss are also different. The main sources of gearbox losses studied at this stage are meshing loss, oil stirring loss, wind resistance loss, bearing friction loss, etc. The simulation software used nowadays, such as AMESim software, has weaken functions in establishing complex mathematical models and logical control $^{[35]}$. Therefore, the model structure of the bearing force calculation module established for the gearbox is relatively large and complex, which increases the gearbox system The complexity of the program can easily cause the program to crash during operation. In addition, the AMESim software comes with the bearing module in the calculation of bearing heat production. The formula used in the calculation of bearing heat generation has low accuracy and is not suitable for the limitations of transient calculation under multiple working conditions ${ }^{[36]}$.

\section{Simulation example of gearbox heat transfer analysis}

Taking the heat transfer analysis of gearbox gears based on Fluent software as an example, the simulation includes the following steps:

(1) The establishment of heat-fluid coupling simulation model. First, to establish the three-dimensional model of the gearbox gear, and combine with the DMU module of CATIA to complete the establishment of the parameterized geometric model of the gear; the quality of the mesh directly determines the feasibility of the numerical solution and the accuracy of the simulation results, combined with all surfaces of Hypermesh Carry out the division of two-dimensional triangular unstructured mesh, and then use the CFD module in it to generate a three- dimensional tetrahedral fluid domain mesh model by using an interpolation method in the form of no boundary layer. 


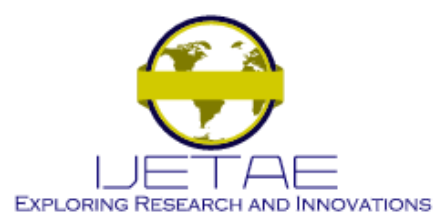

\section{International Journal of Emerging Technology and Advanced Engineering Website: www.ijetae.com (ISSN 2250-2459, ISO 9001:2008 Certified Journal, Volume 10, Issue 11, November 2020)}

(2) To define the boundary conditions and physical parameters of the model. The meshing motion between gears is defined as a continuous rotational motion condition by boundary-type functions, and the boundary between the fluid domain and the solid domain is processed by the wall function method. Then set the method of solving the discrete equation, and use the PISO algorithm to simulate and analyze the internal flow field and convective heat transfer of the gearbox.

(3) To complete the convection heat transfer analysis of the gear. First, the heat dissipation calculation of the gear needs to be completed, including the relative sliding speed, tooth surface contact stress, sliding friction coefficient and frictional heat flow.

(4) To complete the analysis of the convective heat transfer coefficient of the gear teeth. According to the established flow and heat transfer model, boundary conditions and material model, the cyclic loading of heat flux on each small part of the tooth surface is realized by cyclic loading. The convective heat transfer coefficient of each part of the gear teeth can be obtained by calculation.

After setting the above steps, you can load and complete the simulation test. Figure7 is a flow chart of heat transfer analysis of gearbox gears based on Fluent software.

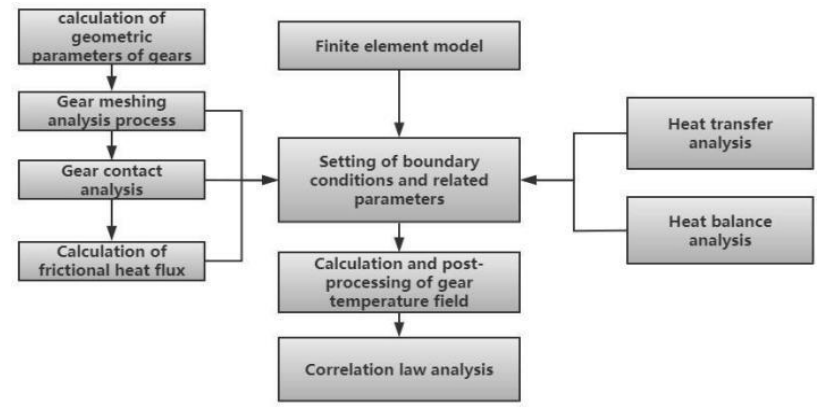

Fig 7 Flow chart of heat transfer analysis of gearbox gears based on Fluent software

The researchers used Fluent software to analyze the heat transfer of gearbox gears. First, the bevel gear transmission model was simplified, meshed, and boundary conditions were set up to establish a heat flow coupling simulation model for the bevel gear transmission. The transmission route and heat balance process, by solving the relative sliding speed of the tooth surface, the contact stress of the tooth surface, and the sliding friction coefficient in the gear transmission process, determine the frictional heat generation and its distribution law. The relative sliding speed affects the amount of frictional heat generation and wear.
The important factor is that the relative sliding speed of the two teeth at the contact point is relatively large at the moment of engagement and the moment of engagement, and the relative sliding speed of the moment of engagement is greater than that of the moment of engagement. Set the driving wheel at different speeds The relative sliding speed of the meshing point; the add-in item for calculating the contact stress of the tooth surface by the elastohydrodynamic value performs a finite element analysis on the contact stress of the bevel gear tooth surface, and the stress distribution of the gear under the torque of $40 \mathrm{Nm}$ is obtained, and the gear meshing process is extracted The mean value of the node stress along the meshing line; then, according to the geometric parameters of the established model, the sliding friction coefficients of the different meshing positions of the entire tooth surface are obtained; finally the distribution of the friction heat flow of the tooth surface along the tooth surface is obtained to complete the transmission of the gear Thermal analysis.

\section{Analysis And Simulation Of Gearbox Noise}

The modeling and Simulation of high-speed gear noise analysis refer to that after completing the basic size design of high-speed gearbox of pure electric vehicle, the modeling and simulation software is applied to model and analyze the designed gearbox, and the gear contact spot test simulation is carried out by the software to find out the gear wheel that produces noise. Then the gear is modified until the transmission error and contact pressure of the gear pair meet the design requirements, and then the contact spot simulation test is conducted by importing the analysis software again ${ }^{[37-}$ ${ }^{38]}$.In the field of gear modeling and analysis, a variety of finite element simulation software has been born, including Adams / view, AVL cruise, Promax, and Masta.

\section{A. Requirement analysis of gearbox noise analysis and simulation}

Gear noise is caused by the dynamic excitation of the gear system, which includes external excitation and internal excitation. The external excitation includes torque fluctuation of driving motor and load, dynamic unbalance of the rotor, clearance of connecting spline, geometric eccentricity, and excitation of relevant parts in the system. The internal excitation is mainly caused by transfer error and the impact of meshing in and meshing out. Therefore, even if there is no external excitation, the gear system will be subject to the internal dynamic excitation and produce noise. Reasonable micro modification of gear can reduce transmission error and meshing impact, improve gear meshing process, make transmission more stable, and reduce gear noise. 


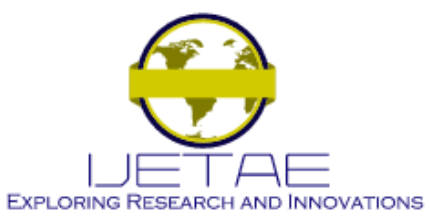

International Journal of Emerging Technology and Advanced Engineering

Website: www.ijetae.com (ISSN 2250-2459, ISO 9001:2008 Certified Journal, Volume 10, Issue 11, November 2020)

With the increasingly strict requirements of vehicle noise control in the world and the increasingly high requirements of consumers for vehicle ride comfort and safety, vibration and noise have become one of the key indicators of vehicle performance. At present, the noise reduction technology of engine and tire is relatively mature, and there are more researches in these aspects. Compared with traditional vehicles, the noise of a purely electric vehicle will be reduced after the power source is changed from engine to motor, and the noise of the gearbox will be more and more obvious, which will become an important source of vehicle noise $^{[39]}$.

\section{B. Difficulties and challenges of gearbox noise analysis and simulation}

Gear noise analysis and simulation need a complete and reliable model system and massive authoritative gear modification data support

(1) The establishment of the model: the process of gear noise is constantly changing. There are a lot of uncertain factors in the actual gear meshing, so it is difficult to describe it with a complete mathematical model.

(2) Model evaluation: due to the complexity of working conditions in a complex environment, the reliability evaluation of the gear simulation model is also facing great challenges. Only the model with high reliability can guide the actual gear modification through the meshing law reflected by the model. At present, a large number of simulation results depend on the experience design of evaluators. How to establish a reasonable evaluation mechanism to feedback and guide the establishment of the model is an urgent problem to be solved at the current stage.

(3) Application of gear simulation model: after the establishment of the high confidence model, how to use the gear noise simulation model reasonably is also a great challenge. Any model has some limitations, so researchers need to set reasonable goals to give full play to the system efficiency and turn the experimental results into decision- making reference.

\section{Example of gearbox noise analysis and simulation}

The simulation of gear noise optimization based on the gear analysis software Masta is taken as an example. Masta software is developed by British saint Transmission Technology Co., Ltd.
It is a large-scale special software with powerful function, wide-coverage, profound technology, and strong practicability for transmission system selection, design, development, and manufacturing. Masta software has a vehicle version, aviation version, and industrial gearbox version. MASTA Vehicle version includes vehicle matching, design analysis, and gear manufacturing. The design analysis part includes three functions: modeling or design, analysis, and optimization. The functions of these three aspects cover three levels: part, component or subsystem, assembly, or system. The role of Masta is to maximize the performance of the drive train and reduce the cost and cycle of design, development, and manufacturing ${ }^{[40]}$.

The simulation of gear noise optimization based on the finite element analysis software of Masta includes several parts: 1) judging the working condition with high noise according to subjective evaluation; 2) analyzing the noise order to lock the noise source; 3) using the Mata modeling and verifying the validity of the modeling; 4) the spot contact simulation test of the gear wheel,as shown in Figure 8;
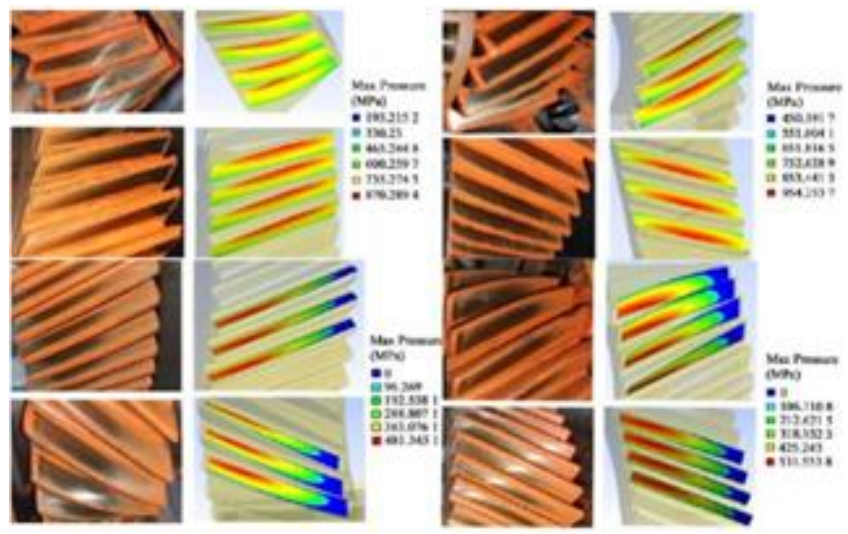

Fig 8 Comparison of bench test and simulation test of contact spots of gears at all levels ${ }^{[40]}$

5) according to the gear modification parameters, transmission error and contact pressure change The relationship is to select the optimal modification parameters to modify the gear; 6) after the gear modification, the mottle contact analysis is performed again with Masta, and the noise bench test is carried out after the requirements are met. Simulation flow chart of gear noise optimization based on Masta finite element analysis software is shown in Figure 9. 


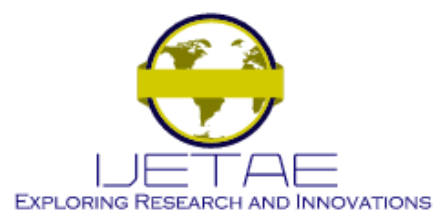

International Journal of Emerging Technology and Advanced Engineering Website: www.ijetae.com (ISSN 2250-2459, ISO 9001:2008 Certified Journal, Volume 10, Issue 11, November 2020)

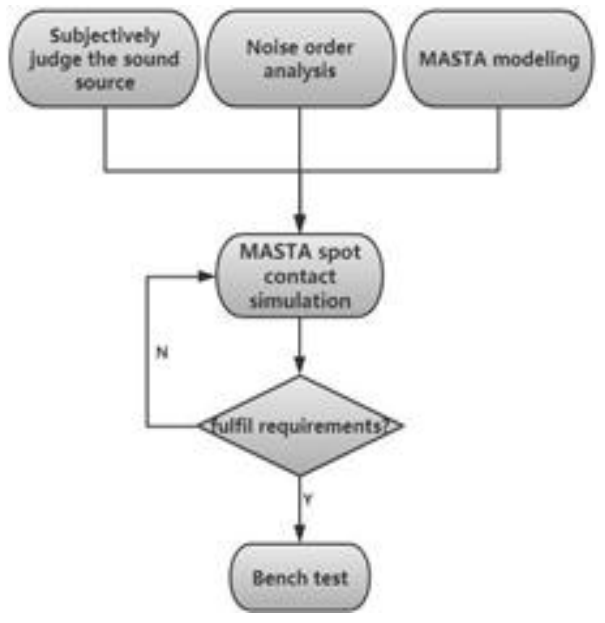

Fig9 Simulation flow chart of gear noise optimization based on Masta finite element analysis software

Peng zhuokai of GAC Research Institute made a subjective evaluation of the noise of the prototype, and it was determined that there was a large gear noise in the working condition of energy recovery. Then the gear noise test and order analysis are carried out. The test results showed that the $21 \mathrm{st}$ and 42 nd order noises are obvious, and then the locking noise comes from the pinion of the first reduction gear pair with 21 teeth. After locking the noise source, the driving system analysis model is created in the gear analysis software Masta. To ensure the accuracy of the model, not only the parameters of the driving system components and their assembly positions are consistent with the design drawings, but also the gear contact spot test is carried out. The contact spot results of simulation analysis are compared with the contact spot results of the test to verify Masta The model created in. The simulation results are in good agreement with the test results. The contact spots of the gears which generate noise are obviously unevenly distributed, resulting in an unbalanced load. The micro modification analysis is carried out on the small gear which produces noise, and the parameters of spiral drum modification, spiral angle modification, and profile pressure angle modification are fully adjusted. To ensure the uniform distribution of contact spots, and no obvious stress concentration, no bias load; at the same time, the transmission error should be considered to reduce the transmission error as far as possible. After gear modification, the simulation test of the contact spot is carried out again. After meeting the requirements, the optimized gearbox is tested on the noise bench ${ }^{[41]}$.

\section{CONCLUSION AND OUTLOOK}

\section{A. Conclusion}

Motor electromagnetic design software companies includes Ansys and Jmag, while gearbox and mechanical design simulation software companies includes SMT Technology, Romax, and Gleason. At present, the software developed by these companies, whether it is motor simulation software or gearbox simulation software, is only for motors or gearboxes. The simulation software has poor compatibility and scalability, poor maintenance, and does not have universality. The thermal simulation software module can only perform the thermal analysis simulation of the motor, but not the thermal analysis of the gearbox, and vice versa., which has led to the current design and analysis of electric vehicle powertrains by some companies still adopting traditional design methods: design, production, and test cycles iteratively until converge. Traditional design methods will obviously result in slow product innovation, repeated work, low technical content, and long cycles, which will seriously affect the healthy and sustainable development of the electric vehicle industry, and will not be able to support the rapid development of the new energy vehicle industry in the future. In addition, the use of independent commercial software for modeling and analysis will cause simulation analysis errors to be superimposed, and the reliability of the overall simulation results is not strong.

\section{B. Outlook}

(1) Add a gearbox mechanical design simulation function module to the drive motor electromagnetic design software developed by Ansys and Jmag, or add motor electromagnetic to the gearbox mechanical design simulation software developed by SMT Technology, Romax, and Gleason Design functional modules to realize the simulation and optimization of the drive motor and gearbox on the same platform.

(2) Develop a mechatronics coupling design analysis simulation software that includes comprehensive simulation analysis of drive motors and gearboxes, to achieve multi-physics two-way coupling performance optimization and data exchange, which will greatly improve drive system design efficiency and design quality and shorten $R \& D$ cycle and reduce $R \& D$ cost. 


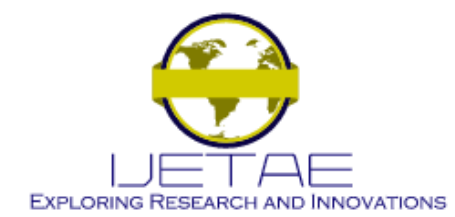

\section{International Journal of Emerging Technology and Advanced Engineering Website: www.ijetae.com (ISSN 2250-2459, ISO 9001:2008 Certified Journal, Volume 10, Issue 11, November 2020)}

\section{Acknowledgements}

This work was supported by the Key Realm R\&D Program of Guangdong Province (2020B090926004, 2019B020223001), Guangdong Provincial Special Fund for Modern Agriculture Industry Technology Innovation Teams (2020KJ120-CJXG)

\section{REFERENCES}

[1] Wen Chuanxin, Wang Peixin, Hua Wei. Driving Technology of Electric Vehicles: Current Developments and Future Prospects[J]. Micromotors, 2019,052(010):103-109.

[2] Yan Jie, Fu Wenxing, Zhang Kai, et al. Review of the Weapon System Simulation Technology[J]. Journal of System Simulation, 2019,31(09):1775-1789.

[3] Chen Bowen. Research on Electromagnetic Design and Highprecision Simulation Modelling of Permanent Magnet Synchronous Motor for EV Applications[D]. Zhejiang university,2020.

[4] Lu Haibin, Qian Sheng, Chai Zhaoliang. Optimization Design of PMSM for Electric Vehicles[J]. Auto Electric Parts,2019(05):12-15.

[5] Zhang Yifu. Research on Permanent Magnet Synchronous Motor with V-shaped Magnet Structure for Electric Vehicles[D]. Shandong University, 2019.

[6] Huang Qi, Chen Xiang, Luo Ling, et al. Design of Permanent Magnet Synchronous Motor Controller for Electric Vehicle[J]. Electric Machines \& Control Application,2019,46(10):84-91.

[7] Ma Changjun, Gao Jian, Liu Bo, et al. Thermal Modeling and Simulation of Permanent Magnet Driving Motor Based on ANSYS[J]. Marine Electric,2016,36(10):9-13.

[8] Fu Pengrui. Research On Electtromagnetic And Temperature Rise Characteristics Of High Torque Density Permanent Magnet Synchronous Motor[D]. Harbin Institute of Technology,2019.

[9] Alemi-Rostami M, Rezazadeh G, Alipour-Sarabi R, et al. Design and Optimization of a Large-Scale Permanent Magnet Synchronous Generator[J]. Entia Iranica,2019.

[10] Chai F, Li Y, Pei Y, et al. Analysis of Radial Vibration Caused by Magnetic Force and Torque Pulsation in Interior Permanent Magnet Synchronous Motors Considering Air-Gap Deformations[J]. IEEE Transactions on Industrial Electronics,2018,66(9):6703-6714.

[11] Yang Dingwei. Vibration and Noise Analysis of Permanent Magnet Motors in Electric Vehicle[D]. Chongqing University,2019.

[12] Zhang Xin. Calculation and Analysis of Electromagnetic Vibration of Interior Permanent Magnet Synchronous Machine[D]. Shandong University,2020.

[13] Liu Yanlong. Acquiring of Dynamic Load Spectrum About Automobile Transmission and Editing of Load Spectrum for Test Bench[D]. Chongqing University of Technology,2015.

[14] Zhao Fangzhou, Lu Jianwei, Luan zhen, et al. Rigid -flexible coupled modeling and fatigue life prediction of transmission gear system[J]. Journal of Hefei University of Technology(Nature Science),2019,42(04):467-472+492.

[15] Gao Na, Feng HuiHua, Yang ShiQiu, et al. Dynamic Analysis of The Gear-box Case Structure Based On Stiffness Coupling and Its Life Estimation of Vibration Fatigue[J]. Journal of Mechanical Strength. 2017,39(01):221-225.

[16] Liu Xuan. Optimization Design and Reliability Analysis of the Planetary Gear Mechanism for Automatic Transmission of Electric Vehicles[D]. Shijiazhuang Tiedao University,2018.
[17] Huang Qingqing. Contact-stress Fatigue Life Research for Gears in Blade Electric Vehicles 2 AMT[D]. Hefei University of Technology,2016.

[18] Glodež S., Šori M. Bending Fatigue Analysis of PM Gears[J]. Key Engineering Materials,2017,4520.

[19] Liu Na, Wang Rui, Tian Zhengfang. Fatigue Life Analysis of Transmission Gears Based on FE - SAFE[J]. Weifang Higher Vocational Education,2017,13(03):51-54.

[20] Wang Chunyu. Analysis and Test of a certain type of Transmission[D]. Northeastern University,2016.

[21] Li Z, Mao K. Frictional Effects on Gear Tooth Contact Analysis[J]. Advances in Tribology,2013:783-787.

[22] Hu Wanhui. Study on Gear Strength of Automobile Transmission Based On FEM[D]. Chongqing University,2018.

[23] Hailu H N, Redda D T. Design and Fatigue Analysis of an E- Drive Transmission System of Single-Speed Gear for Electric Vehicle[J]. International Journal of Engineering Research in Africa,2020,48:92107.

[24] Xu Ran. A Research on Accelerated Fatigue Test Method for commercial vehicle Transmissions[D]. Chongqing University of Technology,2017.

[25] Douglas C E, Thite A. Effect of lubricant temperature and type on spur gear efficiency in racing engine gearbox across full engine load and speed range $[\mathrm{J}]$. Archive Proceedings of the Institution of Mechanical Engineers Part $J$ Journal of Engineering Tribology,2015,229(9).

[26] Wang Zhiyu. Simulation and Experimental Study of Thermal Assembling Process of Transmission Gear[D]. Hefei University of Technology,2016.

[27] CHEN Jinming. Finite Element Analysis About Temperature Field, Thermal Stress and Thermal Deformation of Gear in Quenching Process[J]. 2011,040(006):181-184.

[28] Fu Sinan, Ling Shuyuan. Calculation of power loss and heat dissipation of gear reducer[J]. Mechanical,1988(05):2-7.

[29] Wang Zhongda. Simulation Analysis on Fluid and Temperature Field of Bevel Gears Based on Heat-Fluid Coupling[D]. Jilin University,2015.

[30] Zhou Xiaoshuai. Research on thermal deformation of the holes on the gear box of automobile[D].Hefei University of Technology, 2015.

[31] Concli F, Gorla C, Della Torre A, et al. Churning power losses of ordinary gears: a new approach based on the internal fluid dynamics simulations[J]. Lubrication ence,2015,27(5):313-326.

[32] Sina Modaresahmadi, Javad Khalesi, Kang Li, et al. Convective heat transfer analysis of a laminated flux focusing magnetic gearbox[J]. Thermal Science and Engineering Progress,2020,18.

[33] Paul Walker, Bo Zhu, Nong Zhang. Powertrain dynamics and control of a two speed dual clutch transmission for electric vehicles[J]. Mechanical Systems and Signal Processing,2017,85.

[34] Miad Yazdani, Marios C. Soteriou,Fanping Sun, et al. Prediction of the thermo-fluids of gearbox systems[J]. International Journal of Heat and Mass Transfer,2015,81.

[35] Wei Li, Sun Jingdong, Yu Jiapeng. Analysis of dynamic characteristics of a multi-stage gear transmission system[J]. Journal of Vibration and Control,2019,25(10).

[36] Zhang Qingyong, Wang Yaru, Lin Weiping. Analysis on Dynamic Contact Performance and Microscopic Trimming Optimization of Pure Electric Bus Transmission Gears[J]. Ferroelectrics,2020,566(1). 


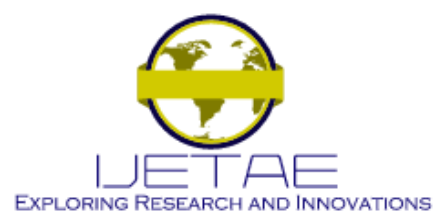

International Journal of Emerging Technology and Advanced Engineering

Website: www.ijetae.com (ISSN 2250-2459, ISO 9001:2008 Certified Journal, Volume 10, Issue 11, November 2020)

[37] Zhang Mingzhe. Dynamics Simulation and Vibration Characteristic Analysis of Two-speed Transmission for Electric Vehicle[D]. Jilin University,2020.

[38] Cui Guokai. Research on Vibration and Noise Analysis and Optimization for Transmission in Pure Electric Bus[D]. Jilin University,2020.

[39] Pan Xiaodong, Liu Xianghuan, Li Chao. Investigation on NVH Performance Optimization of BEV High Speed Gear Transmission[J]. Journal of Chongqing University of Technology(Nature Science), 2017,31(11):25-31.
[40] Wang Liang. Structure Design and Analysis of Pure Electric Vehicle Gear Box[D]. Jilin University,2015.

[41] Peng Zhuokai, Liu Jing, Xiong Fei, et al. Study on Gear Whine of Hybrid Power System based on Contact Patch and Micro Modification[J]. Journal of Mechanical,2020,44(09):14-20. 